\title{
Applications of social networking for universal access in online learning environments
}

\author{
Chia-Wen Tsai ${ }^{1}$
}

Published online: 16 February 2016

(C) Springer-Verlag Berlin Heidelberg 2016

Social networks and related technologies have continued to gain importance in modern people's worlds [3]. Through social networking services (SNSs), individuals are able to contact family, friends, even strangers, through the ease and comfort of computers or mobile Internet devices [6]. Increasingly more importance is attached to the application of SNSs in the educational field [9]. Researchers indicate that SNSs such as Facebook are one of the latest examples of communication technologies that have been widely adopted by learners and, accordingly, have the potential to become a valuable resource to support collaborations and educational communications among teachers and learners $[8,11]$. However, there is relatively little theoretical and empirical attention paid by social researchers and educators to the form and nature of learning in such contexts $[5,7]$. Modern educators should devote more effort to investigate and explore the potential applications of SNSs and integrate them into online or blended courses to improve students' learning and teachers' teaching.

In this regard, the guest editor facilitated this special section to collect research studies that explore various applications of SNSs to help students learn better. The authors of the seven papers in this special section present different approaches and several applications of social networking in online learning. Each of these seven papers went through three rounds of review.

In the first paper "Effects of conformity and learning anxiety on intrinsic and extrinsic motivation: The case of

Chia-Wen Tsai

jawen12b@gmail.com

1 Department of Information Management, Ming Chuan University, 250 Zhong-Shan N. Road Sec. 5, Taipei, Taiwan, ROC
Facebook course groups" by Jerry Chih-Yuan Sun, Yun$\mathrm{Ru}$ Syu, and Yu-Yan Lin, the authors investigate whether students' conformity and learning anxiety influence their intrinsic and extrinsic motivations while participating in Facebook course groups as a complementary tool. Three scales, namely conformity scale of students using Facebook course groups, learning anxiety scale, and intrinsic and extrinsic learning motivation scale, are used as measurements in this study. The authors apply structural equation modeling to analyze the collected data, and indicate that conformity behavior affected by environmental interactions could positively predict intrinsic and extrinsic learning motivation, as learning anxiety could negatively predict intrinsic motivation. However, the authors also report the limitation of the insufficient sample size and suggest that future studies should recruit learners from different grade levels as samples to extend understanding.

The second paper "Key determinants for intention to use social media for learning in higher education institutions," by Vimala Balakrishnan, explores the factors that affect students' intention to use social media for learning in tertiary institutions. In this study, 300 students participated in an online survey. The author developed a social media model, titled "Social Media Acceptance Model (SMAM)," by adapting factors from the Unified Theory of Acceptance and Use of Technology (UTAUT) and the E-Learning Acceptance Model (ELAM), to investigate students' intention to use, and examine their actual use of social media for learning. The author reports six factors that influence students' intention to use social media for learning: Self, Communication Functionality, Effort/Influence, Performance, Information and Communication Technology (ICT) Facility, and Collectivism. It is reported that the last two factors were found to be insignificant, 
while Self had the strongest effect on students' intention to use social media for learning. These six factors contributed to $71 \%$ of students' intention to use social media for learning, which represents strong evidence of the model. Finally, the respondents also expressed that social media, such as Facebook, can be used for learning activities as they can support students' collaboration, sharing, and communication.

Tien-Chi Huang, Yu-Lin Jeng, Kuo-Lun Hsiao, and BiRung Tsai, in their paper "SNS collaborative learning design: enhancing critical thinking for human-computer interface design," present a Project-based Cloud Learning (PBCL) model integrated with various Google services to develop students' critical thinking abilities. The authors conducted a one-group pretest-posttest experiment in a human-computer interface (HCI) design course. Both quantitative and qualitative data were collected and analyzed in this study. The authors report that the practice of PBCL could be more helpful than disposition for students in their development of critical thinking skills. The qualitative data indicate that the experimental subjects hold a positive perspective on integrating SNS and various Google services to the HCI course to improve project design and critical thinking skills. This PBCL model could be beneficial and deepen students' impression of learning content.

In the paper "Online training for business plan writing through the World Café method: The roles of leadership and trust," Wen-Long Chang adopts the popular forum of World Café for the preparation of business plans hosted by the Taiwanese government. The online World Café could serve as a forum for the formation of a community aimed at facilitating cooperative learning, enhancing thinking, and approaching entrepreneurship. The author concluded that this approach is an effective tool and has a significant positive effect on developing students' ability in writing business plans. The author further analyzed the collected data from the viewpoint of business administration. That is, the author revealed that, under transformational leadership, a stronger sense of trust can be helpful for students' learning performance. On the other hand, if the trust level is low, transactional leadership is much more effective than transformational leadership on the promotion of learning effects.

Vimala Balakrishnan (also author of the second paper), in the paper entitled 'Book2U and students' learning styles: The effect of learning styles on intention to use a social media enabled tool," explores the effects of students' learning styles on intention to use a social media enabled tool developed based on the Push-Pull-Mooring (PPM) theory, named "Book2U" which focuses on three learning styles: collaborative, independent, and participative. The questionnaire used in this research included the following five factors: Academic Reasons, Social Networking, Convenience, Self-efficacy, and Ease of Use. The author reports that learning styles have significant effects on learners' intention to use Book2U. In addition, Social Networking, Self-efficacy, and Convenience were found to have significant effects on learners' intentions to use Book2U for their learning, no matter what their learning style is. The author also suggests that educational institutions can develop specific tools focusing on the key factors to engage students in learning with different learning styles.

The sixth paper "A study of peer coaching in teachers' online professional learning communities," presented by $\mathrm{Si}$ Zhang, Qingtang Liu, and Qiyun Wang, collects self-reports about peer coaching behavior from 376 members of online professional learning communities (PLCs). Peer coaching could consist of academic, technical, emotional, and reflective support; it is concluded that peer coaching among teachers in these online PLCs was mainly to provide the last two types of support. Based on the collected data, the authors also report that teachers rated themselves slightly above the average in all the factors of peer coaching. The issues of gender, relative age, grade level of teaching responsibility, and teaching experience are also discussed in this paper.

In the last paper of this special section, titled "Resistance towards wiki: Implications for designing successful wiki-supported collaborative learning experiences," Farrah Dina Yusop and Siti Mariam Muhammad Abdul Basar present qualitative research conducted on the resistance to using wiki among full-time undergraduate students. In this study, 24 students' reflections, three focus-group interviews, weekly wiki logs and edit history, as well as weekly observations of students' online activities are analyzed. It is reported that students were hesitant to use wikis for collaborative work, and the reasons may be technical (including slow Internet connections outside the classroom and wiki lack of user-friendliness) as well as personal (including anxiety with new technology, mental perception, and lack of commitment toward their learning experiences). The authors also indicate that personal factors have the strongest effect on students' resistance.

Engaging academics in the application of technologies is a relatively new priority in the field of higher education [2, 4]. With the emergence and development of SNSs, they are increasingly used in academia to facilitate and improve students' learning, collaborative problem-solving, and knowledge co-creation [1]. Based on observations and teaching experiences, students may not log in the course Web site every day; however, they usually log in and browse SNSs every day. Educators indicate that the increasing popularity of online programs requires more attention to the design of learning environments to help students learn better 
[10]. The guest editor and the authors of the seven papers for this special section expect that the applications of SNSs and educational technologies for universal access in online learning environments could provide implications and insights for teachers, scholars but also educational departments planning to design course Web sites or provide online courses. It is expected that readers could learn how to apply SNSs and integrate them with different educational technologies and teaching strategies to improve their teaching, and also help their students achieve better learning performance. Finally, the guest editor appreciates all the authors' contributions to the innovative applications of SNSs that could result in better learning outcomes for students, and would like to express appreciation to the reviewers for their constructive feedback and careful review that contributed to the satisfactory completion of this special section.

\section{List of Reviewers}

Kathryn Mac, Callum, Eastern Institute of Technology, Hawke's Bay, New Zealand.

Asunka, Stephen, Ghana Technology University College, Ghana.

Murguía-Romero, Miguel, Universidad Nacional Autónoma de México, Mexico.

Wilfried, Admiraal, Leiden University Graduate School of Teaching, The Netherlands.

Miroslava, Raspopovic, Belgrade Metropolitan University, Serbia.

I-Fan, Liu, Oriental Institute of Technology, Taiwan.

Wen-Lung, Shiau, Ming Chuan University, Taiwan.

Aras, Bozkurt, Anadolu University Yunusemre Kampusu, Turkey.

Yi-Hsuan, Wang, Tamkang University, Taiwan.

Ming-Kuei, Yeh, National Taipei University of Business, Taiwan.

Thomas, Cochrane, Auckland University of Technology, New Zealand.

Chih-Yuan, Sun, National Chiao Tung University, Taiwan. George, Musumba, Dedan Kimathi University of Technology, Kenya.

Zorica, Bogdanović, University Of Belgrade, Serbia.

Cigdem, Turhan, Atilim University, Turkey.

Simon, Atkinson, BPP University, UK.

Noriko, Uosaki, Osaka University, Japan.

Ibrahim, Akman, Atilim University, Turkey.

Tatiana, Osmond, Washington County Community College, USA.

Kenneth, Miller, Youngstown State University, USA. Wen-Long, Chang, Shih-Chien University, Taiwan.

Farrah Dina, Yusop, University of Malaya, Malaysia.

Celebi, Uluyol, Gazi University, Turkey.
Si, Zhang, Central China Normal University, China.

Siti Mariam Muhammad Abdul, Basar, University of Malaya, Malaysia.

Eugenijus, Kurilovas, Vilnius University, Lithuania. Oyo, Benedict, Gulu University, Uganda.

Karen, Ferreira-Meyers, University of Swaziland, Swaziland.

Chin Lay, Gan, Multimedia University, Malaysia.

Huseyin, Bicen, Near East University, Turkey.

Tien-Chi, Huang, National Taichung University of Science and Technology, Taiwan.

Ahmed Mohamed Fahmy, Yousef, RWTH Aachen University, Germany.

Sarah Hsueh-Jui, Liu, Kainan University, Taiwan.

Juan Santiago, Jimenez, Universidad Michoacana de San Nicolás de Hidalgo, Mexico.

Gülsün, EBY, Anadolu University, Turkey.

Vimala, Balakrishnan, University of Malaya, Malaysia.

Tuğba, Öztürk, Ankara University, Turkey.

Jason, Baker, Regent University, USA.

Sung Youl, Park, Konkuk University, Korea.

Luisa, dall'Acqua, University of Education Schwäbisch Gmünd, Germany.

Hasan, Ucar, Anadolu University, Turkey.

Willa, Louw, University of South Africa, South Africa.

Filiz, Kalelioğlu, Başkent Üniversitesi, Turkey.

Stefanie, Panke, University of North Carolina, USA.

Olzan, Goldstein, Kaye Academic College of Education, Israel.

\section{References}

1. Babu, R.: Blind students' challenges in social media communication: an early investigation of Facebook usability for informal learning. Int. J. Online Pedagogy Course Des 5(1), 58-73 (2015). doi:10.4018/ijopcd.2015010105

2. Browne, T., Hewitt, R., Jenkins, M., Voce, J., Walker, R., Yi, H. Survey of technology enhanced learning for higher education in the UK, p. 2010. Universities and Colleges Information Systems Association, Oxford (2010)

3. Cook, J., Pachler, N.: Online people tagging: social (mobile) network(ing) services and work-based learning. Br. J. Educ. Technol. 43(5), 711-725 (2012). doi:10.1111/j.1467-8535.2012. 01346.x

4. King, E., Boyatt, R.: Exploring factors that influence adoption of e-learning within higher education. Br. J. Educ. Technol. 46(6), 1272-1280 (2015). doi:10.1111/bjet.12195

5. Merchant, G.: Unravelling the social network: theory and research. Learn. Media Technol. 37(1), 4-19 (2011)

6. Myers, S., Endres, M.A., Ruddy, M.E., Zelikovsky, N.: Psychology graduate training in the era of online social networking. Train. Educ. Prof. Psychol. 6(1), 28-36 (2012)

7. Pimmer, C., Linxen, S., Gröhbiel, U.: Facebook as a learning tool? A case study on the appropriation of social network sites from mobile phones in developing countries. Br. J. Educ. 
Technol. 43(5), 726-738 (2012). doi:10.1111/j.1467-8535.2012. 01351.x

8. Roblyer, M.D., McDaniel, M., Webb, M., Herman, J., Witty, J.V.: Findings on Facebook in higher education: a comparison of college faculty and student uses and perceptions of social networking sites. Internet High. Educ. 13(3), 134-140 (2010)

9. Selwyn, N.: Faceworking: exploring students' education related use of Facebook. Learn. Media Technol. 34(2), 157-174 (2009)
10. Trespalacios, J., Rand, J.: Using asynchronous activities to promote sense of community and learning in an online course. Int. J. Online Pedagogy Course Des. 5(4), 1-13 (2015). doi:10.4018/ IJOPCD.2015100101

11. Tsai, C.W., Shen, P.D., Chiang, Y.C.: The application of social networking sites (SNSs) in e-learning and online education environments: A review of publications in SSCI-indexed journals from 2004 to 2013. Int. J. Web-Based Learn. Teach. Technol. 8(3), 18-23 (2013) 